\title{
Barcelona okupa! Una posible historia de la okupación en Barcelona
}

\author{
Barcelona okupa! A possible history of squatting in Barcelona
}

Aritz Tutor Anton · alsumak@gmail.com

UNIVERSIDAD DEL PAÍS VASCO/EUSKAL HERRIKO UNIBERTSITATEA

Enviado: $24 / 04 / 2020$

Aceptado: $19 / 05 / 2020$

\section{Resumen}

La okupación, acto marginalizado y enmarcado durante muchos años a y hacia una comunidad concreta y señalada, en los últimos años ha visto aumentado sus efectivos; lo cual significa que capas más amplias de la población la apropian y la entienden como válido para actuar, reivindicar y crear. La PAH o los movimientos derivados del alterglobalismo o del 15M son ejemplos de ello y muestran la actualidad y versatilidad del movimiento de okupación. El artículo transita los diferentes periodos y momentos del movimiento de okupación en Barcelona, una de las ciudades donde mayor es su presencia y su fortaleza.

Palabras clave: okupación, Barcelona, Centros Sociales Okupados, hibridación, antagonismo.

\section{Abstract}

Squatting, an act marginalized and framed for many years to and towards a specific and designated community, in recent years has increased its strength; which means that broader layers of the population appropriate it and understand it as valid to act, claim and create. PAH or movements derived from alterglobalism or 15M movement are examples of this and show the topicality and versatility of the squatting movement. The article goes through the different periods and moments of the squatting movement in Barcelona, one of the cities where its presence and strength are greatest.

Keywords: squatting, Barcelona, Squatted Social Centers, hybridization, antagonism.

\section{INTRODUCCIÓN}

La okupación abarca diferentes ámbitos y entra en contacto con realidades heterogéneas, aborda problemáticas diversas, acoge variados colectivos y da lugar a interpretaciones muy amplias ${ }^{1}$. Por lo tanto, hablar de okupación es adentrarse en un universo extremadamente

${ }^{1}$ En el País Vasco, por ejemplo, se significó el modelo de gaztetxe (casa de la juventud) como la opción predilecta a la hora de organizar políticamente el colectivo (Galdeano, 2016). Gaztetxe no sólo es la adaptación idio- 
complejo y que, de hecho, es hoy más heterogéneo que nunca (Martínez y Cattaneo, 2014; Cattaneo y Tudela, 2014). La okupación como fenómeno remite a la acción de okupar, al mismo hecho de entrar en una propiedad ajena y habitarla (ya sea como vivienda o para alojar un proyecto político, o ambas). La okupación vista así se constriñe a su estética, al mero hecho de estar "usurpando" un lugar. Esta visión es muy dada a la reducción simplona pues se restringe la okupación al ritual de abrir un edificio en desuso. Esta acción disruptiva se convierte en el símbolo de la okupación y ensombrece y oculta sus otras dimensiones. Las deliberadas simplificaciones se extienden igualmente al terreno cultural - los okupas como tribu urbana, con unas costumbres y vestuario originales- y a la edad de sus componentes -naturaleza juvenil del movimiento, como rito pasajero que satisface necesidades temporales de alojamiento o de fijación de identidad-(Martínez, 2007a), limando sus expresiones más politizadas. Esta perspectiva es la que toman la mayoría de los medios de comunicación la mayoría de las veces, centrándose en este determinado aspecto, obviando sus fines y complejidades y presentando, en consecuencia, el fenómeno como único y unánime (Martínez y Cattaneo, 2014), ignorando sus variadas y heterogéneas ramificaciones.

Debido a este intrincado y variopinto contexto, este artículo tratará de acotar los alcances espaciales y temporales. Así, el objetivo es analizar la línea cronológica que sigue el movimiento específicamente en el área metropolitana de Barcelona, con las evoluciones y hechos más distintivos de su historia reciente. El punto de partida se ha establecido tras el fin de la dictadura, con las primeras acciones urbanas de importancia del movimiento okupa y autónomo, influenciado por movimientos europeos similares que tienen su origen a principios de los años 70. El texto es eminentemente teórico y por ello la metodología consistirá en la profunda revisión bibliográfica de literatura académica y activista.

El estudio es interesante no únicamente porque se adentra en los vericuetos y giros de uno de los movimientos contestatarios más potentes y vitales de la actualidad, sino porque al mismo tiempo permite seguir los acontecimientos sociales, observar cómo se ve afectado el movimiento por el momento histórico y ver cómo se insertan y se influyen mutuamente con otros movimientos sociales. La elección del caso de Barcelona se justifica por ser uno de los nodos más activos del movimiento a nivel estatal, al considerarse probables herederos de los agitadores de la Rosa de Foc.

\section{LA OKUPACIÓN, PASO A PASO}

Los primeros compases del movimiento de okupación contemporáneo comienzan en Países Bajos, Alemania, Reino Unido, Francia, Suiza e Italia en la década de los $70-\mathrm{y}$ últi-

mática de lo que en otras partes del Estado se llama Centro Social Okupado, Ateneo o Casal, sino que encierra también una singularidad en su composición. Los gaztetxes cobijan un espectro ideológico amplio y que con el tiempo ha ido evolucionando, adoptando desde las demandas del sector más radical de la juventud, hasta las características y necesidades de otros movimientos políticos que abarcan diferentes esferas de poder, desde la expresión más heterodoxa hasta algunas formas institucionalizadas. 
mos años de los 60- (Martínez, 2011; Staniewicz, 2011). En el estado español, esta práctica llega y se consolida a principios de los 80. Este desfase respecto a otras ciudades europeas se debe a la represión de la dictadura. La llegada de la democracia, la existencia de múltiples partidos políticos y las elecciones libres hicieron que mucha gente se ilusionara con haber conseguido la libertad y se volcará con la recién estrenada institucionalidad ${ }^{2}$, lo que debilitó el desarrollo de formas autónomas de organización. El fuerte contenido deslegitimador del discurso formal democrático que el movimiento lleva implícito ha tenido uno de sus principales impactos simbólicos el ejercer de puente entre una generación derrotada en la transición, que había quedado aletargada, y las actuales generaciones que luchan por la transformación radical de la sociedad (González et al., 2002). De igual manera, «cabe pensar en una cierta continuidad entre el movimiento vecinal y el de okupación como dos tipos distintos y correlativos de movimientos urbanos de carácter progresista» (Adell y Martínez, 2004; cursiva en el original). No hay que olvidar que junto a las Asociaciones de Vecinos se implicaron también, sobre todo en el periodo 1975-1979 (Casademunt et al., 2006: 28), colectivos culturales y profesionales que ayudaron a que las propuestas y contrapropuestas urbanas tuvieran una visión global y técnica (el Plan Popular de Santa Coloma de Gramenet, por ejemplo).

A la hora de narrar la historia del movimiento hay diferentes periodizaciones y las fases en las que se ha dividido e inscrito al movimiento han ido variando según pasaban los años y la perspectiva se ampliaba (Martínez, 2001; Martínez, 2002b; Martínez, 2007b). Dos alternativas recientes a la periodización escogida en el texto suponen la que, por un lado, elaboran Cattaneo et al. (2015) para Barcelona y en la que optan por las etapas 1977-1996 (prehistoria e historia temprana), 1996-2001 (era dorada), 2001-2006 (madurez), 2006-2011 (bifurcación) y 2011-presente (15M y más allá), y, por otro lado, la que confecciona Martínez (2014) para Madrid (aunque pueda proporcionar trazas de las tendencias del Estado español), y en el que distingue tres ciclos con dos fases internas. A saber, «Los detonantes» del año 1975 al año 1995 (subdividido entre el periodo 1977-1980 —Los primeros okupas como los inmediatamente precedentes de los CSOs, pero no como movimiento okupa- y 1985-1995 — Primeros okupas autonomistas y el crecimiento-), «Criminalización y especulación global» del año 1996 al año 2010 (subdividido a su vez entre el periodo 19962003 - La reacción a la criminalización y el auge del Movimiento por la Justicia Global—y 2004-2010 —El desarrollo estable desde el boom económico a la crisis en el Madrid globalizado-), y finalmente «El movimiento 15M» desde el año 2011 hasta hoy.

En lo que respecta al conjunto de Catalunya, Fernández Gómez (2010) fija el comienzo de las primeras okupaciones entre los años 1984 y 1986. Continúa con el periodo 1987-1996, que representa la reactivación de la okupación y la consolidación de la vía autónoma, con el periodo 1997-1999, en el que se produce un crecimiento cuantitativo y, finalmente, el

\footnotetext{
${ }^{2}$ La democratización de la política municipal tras 1979 incluía en sus presupuestos básicos la búsqueda activa de la participación popular (la ilusión de participar, la ilusión de participación) por parte de las instituciones (Fernández Soto, 2005), como medio de tomar fuerza en la nueva situación y legitimarse.
} 
periodo que va del 2000 al 2009, que el autor considera como el de la muerte de la okupación. Aunque Fernández Gómez refiere la muerte del movimiento a causa de su división, de su giro hacia posiciones ciudadanistas y moderadas alejadas de su origen libertario, es obvio que le falta recorrido temporal (tal como ocurre en otras periodizaciones ya descritas).

En este caso se tomará la periodización (y narración de hechos) que establecen Cattaneo y Tudela (2014), por su capacidad explicativa en lo cronológico (permite seguir las evoluciones de sucesos y transformaciones ideológicas) y en lo histórico (posibilita la conexión con circunstancias contextuales y acontecimientos más globales; por ejemplo la influencia de las protestas contra la guerra de Irak o el 15M, hechos que no se circunscriben a la dinámica okupa/autónoma, sino que son parte de acciones sociales más generales) y porque su análisis abarca hasta fechas recientes. Los autores distinguen tres etapas: la primera etapa va del año 1984 al año 1994 y se refiere a los primeros okupas, la segunda etapa comprende el periodo 1996-2006 y empieza con el brutal desalojo del cine Princesa y la última etapa arranca en el año 2006 y llega hasta nuestros días, y se caracteriza por una expansión y una descentralización.

\section{1. ¡Patada en la puerta! (1984-1996)}

En la génesis y eclosión de grupos autónomos y okupas, además de las organizaciones vecinales, también había muchas luchas obreras de carácter autónomo³ , porque el área de Barcelona era un polo industrial. El desarrollo de los movimientos okupa y autónomo están influenciados por factores comunes — crisis de legitimidad, cuestionamiento de las relaciones sociales y de poder, controversias políticas - (Steen et al., 2014 $)$ y la misma matriz de lucha engloba a la okupación y a la autonomía. Los Centros Sociales, además de máquinas de guerra singulares (Machuca, 2016), forman parte de un mismo movimiento autónomo (Hodkinson y Chatterton, 2006) o un mismo momento de lucha (cual herramienta). Ya a mediados de los 70 en Alemania emerge una formación multifacética conocida como los autónomos que nacen en torno a las luchas antinucleares y ponen distancia frente a la organización marxista-leninista (Katsiaficas, 2013). Este grupo incluía al movimiento pacifista y al movimiento contracultural y de la okupación, por ejemplo ${ }^{5}$. La autonomía, por lo tanto, se imbrica perfectamente y en consonancia con la okupación ${ }^{6}$ y por ello a veces se utilizarán indistintamente ambas denominaciones.

\footnotetext{
${ }^{3}$ La huelga de la Harry-Walker de Sant Andreu o la de Roca en Gavà —con la decisiva implicación también de las mujeres - son dos ejemplos, entre muchos (Espai en Blanc, 2008).

${ }^{4}$ Como muestras de esta realidad están algunos capítulos de este libro: el de Vasudevan sobre Berlín, el de Karpantschof y Mikkelsen sobre Copenhague o el de Foltin sobre Viena (y los Spontis). En estas experiencias la okupación produce geografías autónomas (Pickerill y Chatterton, 2006).

${ }^{5}$ En Italia, Holanda o Reino Unido ocurría algo similar, donde la escena okupa, autónoma y contracultural muchas veces se mezclaban en prácticas y espacios (Milligan, 2016).

${ }^{6}$ Para Fernández Gómez (2010), sin embargo, esta asociación no está tan clara, ya que en su opinión el ambiente autónomo okupa siempre ha dado cabida a algunos sindicatos y partidos, lo cual lo aleja del movimiento autónomo original de los 60 y 70 que rechazaban toda institución mediadora.
} 
En los inicios de los 80, de esos rescoldos (final de la dictadura, emergencia de luchas vecinales y obreras, expansión del asociacionismo, etc.) hubo una recuperación de lo contracultural, de las políticas radicales y un antifascismo herencia del 36. Se abrieron ateneos, centros contraculturales que funcionan como universidades populares (estos centros, que ya existían en el siglo xix, suelen constar de librería, programan actividades, charlas, excursiones, etc.). Estos centros, al igual que ya ocurriera en los años treinta (Ackelsberg y Breitbart, 2017; Navarro, 2016), eran conformadores de identidad de grupo y desarrollaban una conciencia y actitudes críticas, mediante una cultura y educación que transformara individual y socialmente. Un ejemplo que perdura hasta hoy (y último remanente de esas recuperaciones u ocupaciones ${ }^{7}$ vecinales de finales de los 70) es el Ateneu Popular de Nou Barris, un centro cultural de control directo y autogestionado - hoy en día cedido por el Ayuntamiento- para el vecindario de este barrio obrero.

El movimiento por la okupación en Cataluña empieza a perfeccionar su discurso antisistema en la misma práctica de la okupación, entendida como insumisión cotidiana, así como haciendo que la denuncia de la carestía de la vivienda entrara en la agenda pública; en una estrategia que parece más dirigida a la identidad —creación de una contracultura-que al poder (González et al., 2002). La okupación de viviendas ha sido y es una de las motivaciones centrales del movimiento — desde la crítica a las condiciones materiales subsumidas al capital (preciosprohibitivos, especulación, etc.) y con una agenda alternativa para superar las actuales relaciones de poder-, aunque luego el mayor protagonismo y visibilidad lo lleven los Centros Sociales (que tienen una vocación de proyección comunicativa pública). El movimiento arranca inicialmente con la reivindicación de viviendas okupadas, pero son los Centros Sociales los que le conferirán mayor trascendencia, apoyo público y conflicto con las autoridades y políticas locales (Martínez, 2003). Un primer salto innovador y cualitativo será la constitución de los Centros Sociales Okupados/Autogestionados, $\mathrm{CSO}(\mathrm{A}) \mathrm{s}^{8}$, en los que «las funciones de vivienda se han integrado, subordinado o eliminado, a favor de una amplia gama de actividades contraculturales, políticas y productivas abiertas a otros movimientos sociales y a sectores de población» (Martínez, 2007b). Los Centros Sociales se crean con una voluntad de ofrecer modos de vida alternativos (Adell y Martínez, 2004) y suponen una subversión urbana porque desatan la agregación de colectivos, personas y proyectos en un indeterminado flujo de actividades de discusión, protesta, solidaridad y diversión (Martínez, 2003). Con los Centros Sociales, además de pasar de una crítica en clave de vivienda a articular series de luchas más amplias, se forma una nueva autopercepción basada en el deseo y práctica de una transformación sociocultural directa de la sociedad.

\footnotetext{
${ }^{7}$ Los movimientos vecinales utilizaron al inicio la estrategia de ocupar viviendas o espacios para la socialización (Gutiérrez Barbarrusa, 2004).

${ }^{8}$ El término Centro Social es de origen italiano y en Madrid se extendió tras un viaje a Italia organizado por la coordinadora de colectivos Lucha Autónoma (Wilhelmi, 1998) a principios de los 90 (Iglesias, 2007).
} 
La emergencia del movimiento okupa, que tuvo en Barcelona uno de sus epicentros más importantes del Estado ${ }^{9}$ (Díaz-Parra, 2013), coincide al igual que en otras ciudades con la crisis del movimiento vecinal (Martínez, 2007a). Hasta entonces, la disidencia estaba encauzada principalmente por partidos políticos, asociaciones de vecinos y sindicatos, pero una vez acatada la Transición, los partidos se circunscriben al Parlamento, los sindicatos a protestas puntuales (VV.AA., 2015) y a la deriva reformista (Martínez, 2002b: 149) y las Asociaciones de Vecinos entran en declive (Nel·lo, 2015), en favor de los movimientos sociales, que pasan a ser los nuevos portadores del malestar ${ }^{10}$. Éstos necesitan espacios donde reunirse y comienzan a okupar, públicamente, llevando la okupación más allá del conflicto entre el propietario y el okupa, a una disputa con el Estado, y se originan los Centros Sociales.

Los primeros okupas necesitados de espacios musicales, vinculados al Punk (Fernández Gómez, 2010), okupan en el Prat de Llobregat y en el barrio de Gràcia, con la ayuda del Ateneo Libertario de Gràcia. Tanto esta experiencia como la que en Poble Sec estableció la primera okupación pública y politizada sirvieron para un intercambio generacional entre los libertarios que traían la herencia de la Guerra Civil y los jóvenes que empezaban a descollar okupando los primeros locales, pues en cierto modo eran continuadores de la revolución de 1936 y de los ateneos obreros de principios de siglo. La progresión creciente en la creación de centros sociales okupados fue un factor decisivo para abrir la práctica de la okupación a otros sectores juveniles y políticos (Martínez, 2003). En las protestas contra la entrada en la OTAN los punkies y okupas tuvieron por primera vez una repercusión pública y rompieron su marginalidad y en sus enfrentamientos con la policía tejieron lazos de solidaridad. En el año 1986 Barcelona es designada sede olímpica, designación que comportará grandes transformaciones, pero que también supondrá la aglutinación en torno a la idea olímpica de sectores juveniles. El ciclo de protestas estudiantiles de 86-87 hizo que muchos jóvenes experimentaran el asamblearismo y la toma de decisiones horizontalmente. Se intentó crear un Centro Social Okupado, pues hasta entonces los centros sociales eran alquilados. Después vino la lucha contra el servicio militar, que llegó a funcionar como un movimiento autónomo, un movimiento de juventud urbana radical. El año 1987 fue el de la consolidación de la okupación en el área de Barcelona (Fernández Gómez, 2010). En general, la década de los 80 estuvo caracterizada por el gobierno hegemónico del PSOE de Felipe González, la normalización y homologación internacional del modelo capitalista español (entrada en la Comunidad Económica Europea, en la OTAN), la

\footnotetext{
${ }^{9}$ La alarma en los medios de comunicación que están en sintonía con el status quo así lo indica. Por ejemplo este artículo de El País, titulado muy ostentosamente como «Barcelona, capital “okupa”» (García, 2006).

10 Desaparecida la dictadura, las Asociaciones de Vecinos pasaron a principios de los ochenta de la reivindicación a la negociación (Domingo y Bonet, 1998), a un urbanismo dialogado (Cruz Gallach, 2006), en parte debido a la asunción por las administraciones de buena parte de las reivindicaciones del movimiento vecinal. Tras haber producido un embrión de democracia participativa que fiscalizaba las actuaciones urbanas —lo seguirían haciendo, a otro nivel-, con el primer ayuntamiento socialista «muchos intelectuales y profesionales críticos del período anterior pudieran dejar de "pensar" la ciudad para hacerla, para entrar en el templo de la gestión real, y el impacto entre la realidad y deseo forzó una síntesis pragmática, favorecida por e inductora del desmantelamiento de la conciencia crítica representada por el movimiento vecinal» (Vázquez Montalbán, 1990: 327).
} 
doma del pujolisme (sin margen de maniobra por el escándalo de Banca Catalana) y el hecho diferencial catalán y una finalmente lograda paz y consenso social (pese a las protestas descritas, la reconversión industrial o la huelga general de 1988).

En el año 1989 se okupa la emblemática Kasa de la Muntanya, en un antiguo cuartel, y más tarde, entre el año 1994 y el 1995 se organiza la primera asamblea okupa, y finalmente en 1995 nace Info Usurpa, el primer medio interno de los okupas de Barcelona (Herreros, 2004). La contrainformación es una herramienta importante para puntualizar y dar voz a los Movimientos Sociales, para luchar contra la descontextualización de la información de los medios de comunicación ${ }^{11}$. La estigmatización de movimiento y su folklorización -lo cual lo estereotipa y desactiva su potencia política, por un lado, y silencia e invisibiliza sus motivaciones sociales, por otro lado- por parte de los medios de comunicación actúa codo a codo con la represión policial y jurídica. Por eso es vital la conformación de (alta)voces propios, tal como se aprecia en este vehemente texto — contextualizado en Madrid- de finales de los 90:

«¿Qué es el movimiento de okupaciones? ¿Es un movimiento o sólo una tribu marginal? ¿Es la okupación una actitud delictiva? Son preguntas que se hará mucha gente de la izquierda sociológica de este país, sobre todo a partir de que el "fenómeno okupa” ha tomado cuerpo a través de los medios de comunicación. No es que no existiera antes, pero parece que ahora la prensa está interesada en sacar a la luz nuestra lucha, se puede hablar ahora de "moda okupa”, y es que la prensa puede mentir tanto callando, arrinconándonos en el silencio como nos hacía antes, como puede mentir hablando hasta la saciedad de un fenómeno social (...) Arrinconados en el territorio del silencio por la prensa, creamos nuestras formas y medios de comunicación: panfletos, pintadas, debates abiertos, los propios espacios de los centros sociales, pero también nuestras revistas, radios libres, nuestra agencia de comunicación alternativa (la UPA, MOLOTOV), periódicos no formales como El Fuego y la Piedra, nuestras distribuidoras de material alternativo y disidente. Aislados, olvidados por la izquierda (la vieja izquierda), trabajamos, sufrimos, nos equivocamos mil veces, gozamos y avanzamos pese a todo.» ${ }^{12}$

\subsection{La extensión del movimiento autónomo (1996-2006)}

El año 1996 fue un punto de inflexión porque entró en vigor el nuevo Código Penal (y porque, en general, la presidencia del Estado cambió al PP), que suponía la criminalización legal del movimiento (González et al., 2002), pero quizá llego tarde, porque el movimiento tenía adquiridas ya experiencia y una fortaleza organizativa (Martínez, 2002b: 165). El empeño policial en buscar la marginación y deslegitimación política del movimiento llevó a que se conectara (con un sesgo absolutamente interesado y selectivo) la actividad de ETA con los okupas (Fernández Gómez, 2010). Esta estrategia no era nueva para el movimiento,

11 En gran medida, las protestas que no salen en los medios no existen (Alcalde, 2004).

12 https://www.lahaine.org/mm_ss_mundo.php/acerca-de-los-okupas-y (consultado el 22 de abril de 2020) 
pues ya se había llevado a cabo en Europa con anterioridad. Así, en la Alemania de los 70 se implementó una estrategia que perseguía un fin parecido, vinculando okupas con grupos de guerrilla urbana (Steen et al., 2014: X-XI) y en Italia los Centros Sociales fueron golpeados por la policía pretextando que eran lugares de subversión violenta y tráfico de drogas (Ruggiero, 2000).

Además, en Barcelona, el año 1996 vino marcado por el violento desalojo del cine Princesa. El edificio, situado en pleno centro de la ciudad, fue okupado para denunciar la elitización producida a raíz de los Juegos Olímpicos y también por su simbolismo al haber acogido reuniones obreras justo después de la muerte de Franco. Su desalojo - al igual que dos años antes el del CSO Minuesa ${ }^{13}$ en Madrid- fue muy simbólico y resultó un revulsivo para el movimiento y su visibilización (la espectacularidad del desalojo permitió conectar y comunicar con la opinión pública). De hecho, tras el desalojo y el endurecimiento del Código Penal hubo un efervescente aumento cuantitativo de las okupaciones (Martínez, 2002b: 154; Fernández Gómez, 2010) y fue el bautismo militante — tanto para activistas del movimiento okupa como para otras corrientes - de una generación (Garcés, 2018).

A pesar de la abrupta respuesta del gobierno, varias casas fueron okupadas en los meses posteriores (como destacables están La Hamsa en Sants, El Palomar en Sant Andreu y el Casal de Joves en Gràcia). En diciembre de 1996 fue okupado Kan Pasqual, el primer brote de la okupación rurbana; una combinación de características urbanas y rurales desarrollado en el borde entre la ciudad y el campo. En aquellos años hubo más okupaciones significativas (como Les Naus en Gràcia o Can Vies en Sants) y se reforzaron las redes de colaboración y los medios de difusión y conocimiento mutuo - con la creación y refuerzo de listas de coordinación y medios de comunicación como Info Usurpa o Contra Info y la existencia de un centro social, Espai Obert, que hacía las veces de nodo y acogedor de encuentros y reuniones- (Cattaneo y Tudela, 2014). Según González et al. (2002), el movimiento se expandió ${ }^{14}$ pasando las casas okupadas en el Principado de 40 a 150 entre 1996 y 1998, concentradas mayoritariamente en Barcelona. Estos espacios se convirtieron en verdaderos motores culturales y comunitarios de los barrios donde se impulsaban (Desbordes de la cultura, 2017), así como en los principales puntos de articulación de todas las okupaciones y sus actividades y proyectos (Martínez, 2007b).

Finalmente, otro de los parteaguas de este periodo fue la entrada de nuevas sensibilidades en el movimiento, provenientes sobre todo del antimilitarismo y del movimiento estudiantil, que le dotan de una creciente capacidad de movilización e incidencia pública (González

\footnotetext{
${ }^{13}$ «Los golpes más duros de la represión contra los okupas se han vuelto en contra del poder. Los desalojos de Minuesa, Otamendi, y el más reciente de la Guindalera han sido momentos de acumulación de fuerzas, de construcción de unidad; la brutal represión ha sido invertida por el movimiento y nos ha servido como saltos de concienciación. Los desalojos, con su espectacularidad violenta han llevado el debate de la okupación a sectores sociales y territorios a los que con nuestros escasos medios no teníamos acceso». Extraído de: http:// uni-lliure.ourproject.org/wp-content/uploads/2011/10/3-5-acerca-de-los-okupas-y-otras-cuestiones.pdf (consultado el 22 de abril de 2020).

${ }^{14}$ Curiosamente (o no) en Brighton sucedió algo similar, es decir, un fuerte aumento de la actividad okupa tras el intento de criminalización (Needle Collective y los Bash Street Kid, 2014).
} 
et al., 2002). A pesar de que la apertura ya se venía dando desde 1992, ahora se refuerza la red crítica con potencial movilizador y transformador. Asimismo, se comenzaron a dar acciones de concienciación alterglobalistas (el apoyo a la insurrección zapatista) y se visibilizó la participación de mujeres en el movimiento — con la reivindicación de espacios y expresiones de empoderamiento y control como la creación de la Coordinadora Feminista Autónoma- (Cattaneo y Tudela, 2014). De hecho, el movimiento okupa lleva en su seno la idea profundamente feminista de «lo personal es político», y en este sentido, esta visión ha ido ganando protagonismo con el paso de los años ${ }^{15}$. Los CSOs han acogido colectivos feministas (Vasudevan, 2017; Marinas Sánchez, 2004) e incluso se han creado espacios okupados netamente feministas, como la Eskalera Karakola en Madrid (Gil, 2011; González y Araiza, 2015).

A partir del año 2000 se organizaron varias protestas contra grandes eventos que desplazaron el liderazgo de los okupas y sus reivindicaciones en favor de otros movimientos, como el antiglobalizador (1999, 2001, 2002), contra el servicio militar (2000), contra la guerra (2003, 2004), contra el Fórum de las Culturas (2004) o contra la Ordenanza del Civismo (2005, 2006). El movimiento antiglobalización era la reacción al progresivo avance del neoliberalismo como proyecto hegemónico global. La revuelta del Ejército Zapatista de Liberación Nacional (EZLN) es el primer antecedente simbólico, con la irrupción de los pueblos indígenas, haciendo visible una larga historia de resistencia de quienes habían quedado relegados al olvido y a la exclusión (Pastor Verdú, 2007). Una serie de crisis financieras a partir del año 97, junto con la tendencia creciente al desmantelamiento del Estado de bienestar y la excesiva carga de una Deuda Externa draconiana revolvió conciencias y catalizó las protestas de Seattle (noviembre de 1999), Praga (septiembre de 2000), Porto Alegre (enero de 2001) y Génova (julio de 2001). Estas luchas mostraron el cambio de escala en la reivindicación y una cierta internacionalización y globalización (Wieviorka, 2009) de las reivindicaciones, que combinaban la demanda de cambios locales desde una escala transfronteriza (Vargas, 2008) ${ }^{16}$. Esta dimensión internacional es fruto de los tiempos globales (Sassen, 1991), pues las tecnologías de la información hacen accesible las problemáticas y luchas lejanas y la creciente interconexión de la economía hace que estas mismas luchas se conciban bajo el mismo prisma, lo que ha hecho posible un marco de actuación común a nivel mundial ${ }^{17}$. La convergencia o dinamización de una parte del movimiento alter-globalización aumentó los vínculos internacionales y las redes de apoyo y encuentro (Martínez, 2007b; Mudu, 2004; Piazza, 2016; Tilly, 1998), aunque eso no significó subsunción o disolución, pues el movimiento de okupación siguió extendiendo su ex-

\footnotetext{
15 En realidad, esta presencia ha sido notoria desde el inicio. Un ejemplo muy sintomático es el rol que el feminismo jugó en un cierto cambio de estética militante. Si en la década de 1980, las imágenes y épica militante se habían centrado en lo físico, en los enfrentamientos callejeros que obligaban a la policía a retirarse, estimulando una imagen masculina del último luchador callejero, en la década de 1990, esta imagen cambió, en parte debido a la creciente influencia del feminismo y la política queer en el movimiento (Steen et al., 2014).

${ }^{16}$ El vi(r)aje hacia contextos de globalización fue un rasgo común tanto en los NMS como en los NsMS (Bergantiños Franco e Ibarra Guell, 2007).

${ }^{17}$ Los manifestantes de países que no son en absoluto anglófonos llevan pancartas en inglés en atención a los medios internacionales (Neveu, 2002: 144).
} 
periencia de autoorganización social, de reokupaciones y de transmutación de muchos de sus proyectos de intervención social (Martínez, 2005). De hecho, estas alianzas y movilizaciones, repercuten en una mayor visibilidad y un mayor poder para intervenir políticamente (Martínez, 2001) y comunicar sus propuestas. En definitiva, el trasvase de praxis políticas, repertorio de acciones y militantes (Herreros, 2004) entre los diferentes movimientos supuso un enriquecimiento mutuo (Guzmán-Concha, 2015) ${ }^{18}$.

Todos estos momentos movilizaron a personas de espacios políticos diferentes y heterogéneos. Así, se aprovecha el capital alternativo preexistente (la tradición libertaria de la República, vínculos con sectores juveniles y vecinales) y unas ventanas de oportunidad política (alianzas antirrepresivas, con el movimiento antimilitarista, alterglobalizador) y la constante reorientación desbordadora de su discurso y su praxis para encarar una lucha no sectorial, sino contra el todo, planteando la ruptura directa con las estructuras del sistema, no su reforma. No presenta una ideología definida, pluralidad que dificulta la asunción de unos objetivos generales (aunque sólo fueran los antis, a lo que se opone), y conforma una red contractual (y contracultural) de personas y no de organizaciones que se niegan a entrar en espacios de negociación, en espacios o esferas de gobernanza (González et al., 2002).

En el año 2000 se evitó el desalojo (tras varios días de enfrentamientos y la reokupación posterior) de la Kasa de la Muntanya y en el año 2002 se consiguió, después de varios días de resistencia pacífica, permanecer en Can Masdeu, mostrando que las victorias en mantener los proyectos también eran posibles. Gracias a las protestas, los movimientos vecinales y las acciones okupas, muchas personas fueron más conscientes de la colonización del día a día, de la creación de alternativas inspiradas en autonomías ecológicas (ecological autonomy) y de la crítica a las políticas municipales (Cattaneo y Tudela, 2014).

\subsection{Expansión y descentralización (2006-hoy día)}

La okupación de casas continuó, sin que necesariamente derivara en la constitución de Centros Sociales Okupados. Esta apertura y expansión conllevó una mayor variedad en su composición, pero también una menor unidad y cohesión, ya que Barcelona atrajo a personas de otros países a okupar aquí, lo que contribuyó a la difuminación del movimiento, y que se volviera más heterogéneo.

Igual que pasó en Grecia, todos los movimientos tuvieron el soporte de uno o más espacios físicos específicos desde el cual operar, es decir, contaron con la espacialización de sus reivindicaciones y necesidades. En los inicios de los 80 el Ateneo Libertario fue un centro prominente. Después fue el Kafe Volter, donde tomaron forma los movimientos embrionarios punkie y autónomo. El movimiento okupa original de los 90 tuvo el Cine Princesa, la Kasa de la Muntanya y La Hamsa como principales exponentes, mientras que el nuevo

${ }_{18}$ El rechazo a la autoridad y la intermediación, por ejemplo, sirvieron de principios de cohesión para los NMS (Martínez, 2002a). 
milenio vio la emergencia de Can Masdeu, estrechamente asociado al movimiento antiglobalización y la generalización de la preocupación sobre la crisis ambiental. El Forat de la Vergonya también puede verse como ejemplo resistente contra la especulación y el espacio Magdalenas como un referente de la lucha por el derecho a la vivienda. Más recientemente, la Universidad Libre La Rimaia, okupado durante las protestas estudiantiles contra el plan Bolonia, ensanchó y amplió la práctica de la okupación y la autoorganización. La ocupación temporal del edificio del Banco Central - en la Plaça Catalunya-durante la huelga general de septiembre de 2010 y la ocupación de la misma céntrica plaza en Mayo del 2011, demostró cómo el movimiento autónomo puede golpear en el corazón físico y simbólico de Barcelona. El movimiento 15M ayudó a estructurar y establecer mecanismos democráticos para interactuar con y en la política, experimentando, a la vez, con la okupación como herramienta (usando el edificio como artefacto simbólico y aglutinador que reivindica una insuficiencia, un deseo de superar las actuales limitaciones). Al igual que el movimiento alter/anti-globalización ${ }^{19}$ primero (Martínez, 2007b), el 15M reavivó formas de organización política de cariz libertaria y posibilitó la experimentación pedagógica de prácticas sociales alternativas y la revitalización de las okupaciones, tanto de vivienda como de Centros Sociales (Martínez y García, 2013). De hecho, el movimiento 15M contó (en Madrid ${ }^{20}$, por ejemplo) con el sostén infraestructural de los Centros Sociales Okupados. El resultado de este proceso de convergencia virtuosa fue una cadena de acumulaciones activistas que permitieron la reactivación de un nuevo frente de luchas materiales de la multitud ${ }^{21}$ precaria y proporcionó unos fundamentos y recursos socio-espaciales a los múltiples componentes del movimiento (Martínez y García, 2015; Haro y Sampedro, 2011).

\section{A MODO DE CIERRE}

La okupación, como práctica y como teoría, atesora grandes hitos con los que se ha hecho presente en la vida social. El alto grado de impacto de sus propuestas y políticas de acción directa significa que ha llevado a cabo un continuo proceso de actualización que lo pudiera ir armonizando con los movimientos sociales contemporáneos. Así, la okupación se ha convertido en uno de los caminos más directos hacía esta autonomía espacial y política.

La mejor muestra de esta capacidad de adaptación es lo sucedido estos últimos años y que se relata en el último apartado. La okupación, que durante muchos años fue un acto marginalizado y enmarcado hacia una comunidad concreta y señalada, en la última década ha visto

\footnotetext{
19 Asumiendo el rechazo de toda subalternidad respecto de la política institucional y de los partidos políticos existentes o realizando formas avanzadas de democracia local (Fernández Buey, 2007), democracia participativa y autoorganización ciudadana (Pastor Verdú, 2007).

${ }^{20}$ Tanto antes, proporcionado apoyo material, de conocimiento y una red activista coordinada y consolidada, como después, cuando la okupación se convirtió en una herramienta de su lucha (Abellán et al., 2012).

${ }^{21}$ Para Hardt y Negri (2004) la multitud se distingue de otras nociones de sujetos sociales como el pueblo (es uno y está ligado a la identidad), las masas (es uniforme y aunque compuesta por identidades diferentes, los sujetos sociales, su esencia es la indiferenciación) o la clase obrera (únicamente comprende a los obreros industriales o, en un sentido más amplio, a los asalariados) en que es como una red abierta y expansiva que brinda la posibilidad de descubrir lo común, sin apartar las diferencias y reivindicando esa pluralidad.
} 
cómo aumentaba su legitimidad. Estas (nuevas) expresiones territoriales y de prácticas se conjugan especialmente en los CSOs (Centros Sociales Okupados) o CSOAs (Centros Sociales Okupados Autogestionados) ${ }^{22}$ en los cuales se ejerce la autogestión colectiva directa.

Otra de las prácticas de confrontación que esta hibridación o apertura facilitó fueron las okupaciones con fines sociales (para dar salida a una emergencia habitacional, por ejemplo, y no solo como manifestación de una disconformidad política). Así, la okupación, una de las acciones de resistencia más emblemáticas, en cuanto cuestiona y ataca la propiedad privada, fue adoptada para la lucha cotidiana y política de muchos colectivos que anteriormente no lo contemplarían. Los casos del Hotel Madrid ${ }^{23}$, la operativa de la Obra Social de la $\mathrm{PAH}^{24}$ o los recientes casos del Banc Expropiat ${ }^{25}$ y el Patio Maravillas ${ }^{26}$ demuestran que las okupaciones de nuevo cuño se han normalizado y que se ha aceptado la okupación como respuesta válida.

Tal como detalla la cronología, la supervivencia del movimiento okupa ha sido posible gracias a las discusiones llevadas a cabo y que reorientaron algunas de las prioridades y herramientas de lucha. A través de apertura y alianza de los últimos años, catalizados en parte por la (in)surgencia del acontecimiento 15M (como ya ocurrió a principios del milenio con el altermundismo), se han socializado (en el sentido en que se han extendido a personas y colectivos que no aplicaban estas acciones o lógicas en sus praxis política) prácticas no adscritas a las dinámicas de lo institucional (horizontalidad, asambleas, okupaciones, etc.). Esta expansión del modo de hacer okupa, aunque no lleve este distintivo, demuestra la vigencia y necesidad de estas ideas y asegura su fertilidad futura. Su aparente transformación no es más que la obligada adaptación a los nuevos tiempos pero sin dejar de lado los viejos ideales.

\section{BIBLIOGRAFÍA}

Abellán, J.; Sequera, J. y Janoschka, M. (2012). Occupying the \#Hotelmadrid: A Laboratory for Urban Resistance. Social Movement Studies: Journal of Social, Cultural and Political Protest, vol. 11, n. ${ }^{\circ}$ 3-4, pp. 320-326.

\footnotetext{
${ }^{22}$ Englobados, como se ha visto, bajo el término genérico Centros Sociales (concepto que también incluye experiencias socioculturales antagónicas con el sistema establecido y que operan bajo los parámetros del movimiento okupa, entre otros, pero cuyo edificio puede estar en régimen de cesión o alquiler).

${ }^{23}$ La liberación del Hotel Madrid simbolizó la resignificación de la okupación en términos de legitimación para y de la ciudadanía, tendió puentes con la sociedad ampliando el consenso sobre la acción de okupar (tradicionalmente vilipendiada y criminalizada) (Abellán et al., 2012).

${ }^{24} \mathrm{La}$ experiencia radical de la PAH es incuestionable. Sin recurrir a las herramientas del Estado o del mercado consigue, mediante la acción directa hacerse presente en la esfera mediática, política y pública. Y siempre sin subordinarse a ningún poder que lo contradiga, tal como se ve, por ejemplo, en la PAH de Manresa, que rompió con la Agencia Catalana de Vivienda al faltar al acuerdo suscrito (García, 2016).

${ }^{25}$ La persistencia e inteligencia de la estrategia de resistencia (y su repercusión mediática) demuestra que lo simbólico que es el Banc Expropiat para el barrio y los vecinos y la cantidad de soporte social que arrastra con sólo 5 años abierto (por funcionar más como Oficina que como Centro Social, más como punto de encuentro que como lugar de resistencia).

${ }_{26}$ Con legitimidad que llega hasta el Congreso (Gil, 2016).
} 
Ackelsberg, M. y Breitbart, M. M. (2017). The role of social anarchism and geography in constructing a radical agenda: A response to David Harvey. Dialogues in Human Geography, vol. 7, n. ${ }^{\circ}$ 3, pp. 263-273.

Adell, R. y Martínez, M. Á. (eds.) (2004). ¿Dónde están las llaves? El movimiento okupa: prácticas y contextos sociales. Madrid: Catarata.

Alcalde, J. (2004). La batalla de los medios: la definición de la problemática okupa en los medios de comunicación de masas. En Adell, R. y Martínez, M. Á. (eds.), ¿Dónde están las llaves? El movimiento okupa: prácticas y contextos sociales (pp. 227-230). Madrid: Catarata.

Bergantiños Franco, N. e Ibarra Guell, P. (2007). Eco-pacifismo y antimilitarismo: Nuevos movimientos sociales y jóvenes en el movimiento alterglobalizador. Revista de estudios de juventud, 76, pp. 113-127.

Casademunt, À; Alfama, E.; Coll-Planas, G.; Cruz, H. y Martí, M. (2006). Per una nova cultura del territori? Mobilitzacions i conflictes territorials. Barcelona: IGOP, Fundació Jaume Bofill.

Cattaneo, C. y Tudela, E. (2014). ¡El carrer és nostre! El movimiento autónomo en Barcelona, 1980-2012. En Steen, B.; Katzeff, A. y Hoogenhuijze, L. (eds.), The city is ours: Squatting and Autonomous Movements in Europe from the 1970s to the Present (pp. 95-130). Oakland: PM Press.

Cattaneo, C.; Debelle dos Santos, G. y González, R. (2015). Cycles of squatting in Barcelona. En Okupación de viviendas, centros sociales y lugares de trabajo: un taller internacional sobre alternativas autogestionadas. Barcelona: IGOP y Sqek, 21 al 23 de mayo.

Cruz Gallach, H. (2006). Los conflictos urbanísticos: sus causas y sus protagonistas. Una reflexión a partir de la experiencia de Cataluña. Cuadernos de geografía, 80, pp. 183-194.

Desbordes de la Cultura (2017). Desbordar Barcelona. Un relat alternatiu de la cultura a la ciutat. Barcelona: Pol-len.

Díaz-Parra, I. (2013). Acción social en la postmodernidad. Ocupación y movimiento por la vivienda en Sevilla. Revista Andaluza de Ciencias Sociales Anduli, 12, pp. 13-35.

Domingo, M. y Bonet, M. R. (1998). Barcelona i els moviments socials urbans. Barcelona: Mediterrània.

Espai en Blanc (2008). Luchas autónomas en los años setenta. Del antagonismo obrero al malestar social. Madrid: Traficantes de Sueños. 
Fernández Buey, F. (2007). Sobre el Movimiento de Movimientos. Revista de estudios de juventud, 76, pp. 21-36.

Fernández Gómez, F. P. (2010). Okupació a Catalunya (1984-2009). Barcelona: Edicions Anomia.

Fernández Soto, M, (2005). La transición de un espacio excluido a un espacio excluyente. En Congreso de Geógrafos Españoles XIX, Espacios Públicos un debate sobre el Territorio Espacios. Santander.

Galdeano, I. (2016). Gaztetxeak Euskal Herrian. Okupazio-mugimenduaren hedapena. Aldiri. Arkitektura eta abar, vol. I, n. ${ }^{\circ}$ 25, pp. 34-37.

Garcés, M. (2018). Ciudad princesa. Barcelona: Galaxia Gutemberg.

García, G. (2016). La PAH rompe en Manresa con la agencia catalana de vivienda y retoma el control de un bloque cedido. Diagonal Periódico. Disponible en https://www.diagonalperiodico.net/global/29737-la-pah-rompe-manresa-con-la-agencia-catalanavivienda-y-retoma-control-bloque-cedido.

García, J. (2006). Barcelona, capital ‘okupa’. El País. Disponible en http://www.elpais.com/ articulo/espana/Barcelona/capital/okupa/elpepuesp/20061209elpepinac_15/Tes.

Gil, A. (2016). Diputados y concejales participantes del Patio Maravillas reivindican su «legitimidad» ante el juicio por ocuparlo. Eldiario.es. Disponible en https:// www.eldiario.es/politica/Diputados-participantes-Patio-Maravillas-legitimidad_0_522148193.html

Gil, S. L. (2011). Nuevos feminismos. Sentidos comunes en la dispersión. Una historia de trayectorias y rupturas en el Estado español. Madrid: Traficantes de Sueños.

González, R. y Araiza, A. (2016). Feminismo y okupación en España: El caso de la Eskalera Karakola. Sociológica (México), vol. 31, n. ${ }^{\circ}$ 87, pp. 207-236.

González, R.; Pelàez, Ll. y Blas, A. (2002). Okupar, resistir y generar autonomía. Los impactos políticos del movimiento por la okupación. En Ibarra, P.; Martí, S. y Gomà, R. (coords.), Creadores de democracia radical. Movimientos Sociales y redes de políticas públicas (pp. 187-220). Barcelona: Icaria.

Gutiérrez Barbarrusa, V. (2004). Okupación y movimiento vecinal. En Adell, R. y Martínez, M. Á. (eds.), ¿Dónde están las llaves? El movimiento okupa: prácticas y contextos sociales (pp. 115-128). Madrid: Catarata. 
Guzmán-Concha, C. (2015). Radical Social Movements in Western Europe: A Configurational Analysis. Social Movement Studies, vol. 14, n. ${ }^{\circ}$ 6, pp. 668-691.

Hardt, M. y Negri, A. (2004). Multitud. Guerra y democracia en la era del Imperio. Madrid: Debate.

Haro, C. y Sampedro, V. (2011). The new social movements in Spain: The Protests for the Right to Housing as an immediate predecessor of the 15M Movement. En 6th ECPR General Conference. Reykjavík.

Herreros, T. (2004). Movimiento de las okupaciones y movimientos sociales: elementos de análisis para el caso de Cataluña. En Adell, R. y Martínez, M. Á. (eds.), ¿Dónde están las llaves? El movimiento okupa: prácticas y contextos sociales (pp. 129-150). Madrid: Catarata.

Hodkinson, S. y Chatterton, P. (2006). Autonomy in the city? Reflections on the social centres movement in the UK. City: analysis of urban trends, culture, theory, policy, action, vol. 10, n. ${ }^{\circ}$ 3, pp. 305-315.

Iglesias, P. (2007). Algunos centenares de jóvenes de la izquierda radical: Desobediencia italiana en Madrid (2000-2005). Revista de estudios de juventud, 76, pp. 245-265.

Katsiaficas, G. (2013). La subversión de la política: movimientos sociales autónomos europeos y la descolonización de la vida cotidiana. México: Universidad Autónoma de la Ciudad de México.

Machuca, C. (2016). Espacios sociales de gestión ciudadana: una cuestión de necesidad, no de contingencia. Diagonal Periódico - Fundación de los Comunes. Disponible en https://www.diagonalperiodico.net/blogs/funda/espacios-sociales-gestion-ciudadanacuestion-necesidad-no-contingencia.html.

Marinas Sánchez, M. (2004). Derribando los muros del género: mujer y okupación. En Adell, R. y Martínez, M. Á. (eds.), ¿Dónde están las llaves? El movimiento okupa: prácticas y contextos sociales. Madrid: Catarata.

Martínez, M. Á. (2001). «Para entender el poder transversal del movimiento okupa: autogestión, contracultura y colectivización urbana. En VII Congreso Español de Sociología, Salamanca.

Martínez, M. Á. (2002a). Contextos y transversalidad: ¿Aún con los problemas al definir los movimientos sociales?. Inguruak. Revista Vasca de Sociología y Ciencia Política, 33, pp. 119-146. 
Martínez, M. Á. (2002b). Okupaciones de viviendas y centros sociales. Autogestión, contracultura y conflictos urbanos. Barcelona: Virus.

Martínez, M. Á. (2003). Viviendas y Centros Sociales en el movimiento de okupación: entre la autogestión doméstica y la restructuración urbana. Scripta Nova. Revista electrónica de Geografía y Ciencias Sociales, vol. 146, n. ${ }^{\circ}$ 109. Disponible en http://www. ub.edu/geocrit/sn/sn-146(109).htm.

Martínez, M. Á. (2005). La autogestión de viviendas y Centros Sociales Okupados. En Díaz Orueta, F. y Loures Seoane, M. L. (eds.), Desigualdad social y vivienda. Editorial Club Universitario.

Martínez, M. Á. (2007a). The Squatters’ Movement: Urban Counter-Culture and Alter-Globalization Dynamics. South European Society \& Politics, vol. 12, n. ${ }^{\circ}$ 3, pp. 379-398.

Martínez, M. Á. (2007b). El Movimiento de Okupaciones: Contracultura Urbana y Dinámicas Alter-Globalización. Revista de estudios de juventud, 76, pp. 225-243.

Martínez, M. Á. (2011). The struggle to belong. Dealing with diversity in 21st century urban settings. En International RC21 conference 'The Struggle for Social Autonomy: What Have We Learnt about Urban Politics from Squatting in Europe?’. Amsterdam, 7 al 9 de julio.

Martínez, M. Á. (2014). Squatting Practices within Protest Cycles: SocioSpatial Structures or Activist Agency?. City University of Hong Kong

Martínez, M. Á. y Cattaneo, C. (2014). Squatting as an Alternative to Capitalism. An introduction. En Squatting Europe Kollective (ed.), The Squatters' movement in Europe. Commons and Autonomy as Alternatives to Capitalism (pp. 1-25). Londres: Pluto Press.

Martínez, M. Á. y García, Á (2015). Ocupar las plazas, Liberar edificios (The Occupation of Squares and the Squatting of Buildings). ACME: An International Journal for Critical Geographies, vol. 14, n. ${ }^{\circ}$ 1, pp. 157-184.

Martínez, M. Á. y García, Á. (2013). Movimiento 15M, espacio público y luchas provivienda. Zainak, 36, pp. 87-105.

Milligan, R. T. (2016). The Politics of the Crowbar: Squatting in London, 1968-1977. Anarchist Studies, vol. 24, n. ${ }^{\circ}$ 2, pp. 8-32.

Mudu, P. (2004). Resisting and Challenging Neoliberalism: The Development of Italian Social Centers. Antipode. A Radical Journal of Geography, vol. 36, n. ${ }^{\circ}$ 5, pp. 917-941. 
Navarro, J. (2016). Los ateneos libertarios en España (1931-1939). Madrid: La Neurosis o Las Barricadas Ed.

Needle Collective y Los Bash Street Kid (2014). Ebb and Flow: Autonomy and Squatting in Brighton En Steen, B.; Katzeff, A. y Hoogenhuijze, L. (eds.), The city is ours: Squatting and Autonomous Movements in Europe from the 1970s to the Present (pp. 153-178). Oakland: PM Press.

Nel·lo, O. (2015). Movimientos urbanos y defensa del patrimonio colectivo en la región metropolitana de Barcelona. Ciudad y territorio: Estudios territoriales, 184, pp. 311-327.

Neveu, É. (2002). Sociología de los movimientos sociales. Barcelona: Editorial Hacer.

Pastor Verdú, J. (2007). El movimiento ‘Antiglobalización’ y sus particularidades en el caso español. Revista de estudios de juventud, 76, pp. 39-52.

Piazza, G. (2016). Squatting Social Centres in a Sicilian City: Liberated Spaces and Urban Protest Actors. Antipode. A Radical Journal of Geography, vol. 50, n. o 2, pp. 498-522.

Pickerill, J. y Chatterton, P. (2006). Notes towards autonomous geographies: creation, resistance and self-management as survival tactics. Progress in Human Geography, vol. 30, n. $^{\circ}$ 6, pp. 1-17.

Ruggiero, V. (2000). New social movements and the 'centrisociali' in Milan. The Sociological Review, vol. 48, n. ${ }^{\circ}$, pp. 167-185.

Sassen, S. (1991). The Global City: New York, London, Tokyo. New Jersey: Princeton University Press.

Staniewicz, M. (2011). El movimiento okupa como un actor político, social y cultural en una ciudad postcomunista. El caso del centro social-casa okupa Rozbrat en Poznan, Polonia. Revista de estudios de juventud, 95, pp. 123-143.

Steen, B.; Katzeff, A. y Hoogenhuijze, L. (eds.) (2014). The city is ours: Squatting and Autonomous Movements in Europe from the 1970s to the Present. Oakland: PM Press.

Tilly, C. (1998). Conflicto político y cambio social. En Ibarra, P. y Tejerina, B. (eds.), Los movimientos sociales. Transformaciones políticas y cambio cultural. Madrid: Trotta.

Vargas, J. G. (2008). Expresiones del debate de los Nuevos Movimientos Sociales en el contexto de Latinoamérica y México. El Cotidiano, 151.

Vasudevan, A. (2017). The Autonomous City: A History of Urban Squatting. Londres: Verso. 
Vázquez Montalbán, M. (1990). Barcelonas. Barcelona: Empúries.

VV.AA. (2015). Okupa Madrid (1985-2011). Memoria, reflexión, debate y autogestión colectiva del conocimiento. Madrid: Diagonal.

Wieviorka, M. (2009). ¿A dónde va el debate sobre los nuevos movimientos sociales?. En Mestries, F.; Pleyers, G. y Zermeño, S. (coords.), Los movimientos sociales: de lo local a lo global. México: Anthropos/UAM.

Wilhelmi, G. (1998). Lucha Autónoma. Una visión de la Coordinadora de Colectivos (19901997). Madrid: Traficantes de Sueños. 